\section{PREHISTORIC PLAQUE PROVES PLANT PROCESSING}

A new study of dental calculus extracted from archaeological remains from the multi-period Sudanese site of Al Khiday has revealed insights into the consumption, cooking and processing of plants from the pre-Mesolithic, Neolithic and Late Meroitic age. ${ }^{1}$

Morphological analysis of materials sampled from calculus provided evidence for cooking and smoke inhalation, with 'char markers' such as charcoal and soot, and combustion markers, such as fluoranthene and pyrene, consistent with exposure to fire. Starch granules found in three Neolithic samples were enlarged and cracked, indicative of roasting.

Perhaps most interesting are chemical profiles in remains across the three periods that point towards the ingestion of Cyperus rotundus tubers in the pre-agricultural and agricultural period: a time span of more than 7,000 years. C. rotundus, more commonly known as 'purple nut sedge', has been dubbed the 'world's most expensive weed', despite its aromatic and medicinal properties. This suggests our ancient ancestors had greater ecological knowledge than previously thought. Other dental evidence alludes to the use of teeth as a third hand to process plant material for use in other items, suggesting $C$. rotundus was not just used for food.

While meat and protein have been the focus of pre-agricultural dietary interpretation up to this point, this new research provides an argument for varied uses of plants in earlier prehistoric populations and the need for a revolutionised perception of the ecological knowledge of our ancient predecessors.

1. Buckley S, Usai D, Jakob T, Radini A, Hardy K. Dental calculus reveals unique insights into food items, cooking and plant processing in prehistoric central Sudan. PloS One 2014; 9: $\mathrm{e} 100808$

BY LAURA PACEY

\section{BOOK REVIEW}

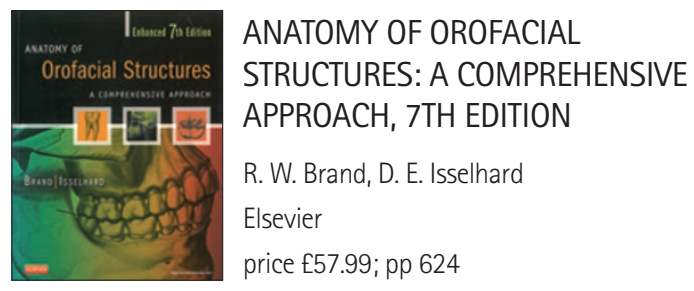

ISBN 9780323227841

As a dental student the task of studying anatomy, histology and embryology can be rather daunting. This text encompasses oral histology, embryology and dental anatomy, as well as head and neck anatomy, in a user friendly style. It provides a good foundation of knowledge of orofacial structures for dental students and students of dental therapy and hygiene. As an added extra, lecturers can access the new online educator support section, where PowerPoint lecture slides and images can be downloaded.

This book leads you through the foundations of oral anatomy, to tooth morphology, the development of the oral cavity and dental structures, and finally head and neck anatomy. It covers each of the areas in a comprehensive yet clear style that engages the reader and applies the information to clinical situations.

The size of this book is a little overwhelming on the surface but, once you start to explore it, you realise it has a lot to offer and much of the space is used for questions at the end of each chapter and unit.
There is also space for note taking and the authors have provided handy, pop-out, pocket-sized flashcards of key anatomical landmarks and tooth morphology.

Each chapter's review questions reinforce learning from the chapter as do multiple choice questions at the end of each unit.

This text goes beyond what would be expected for a text of this title, explaining each aspect in a way that is relevant to the clinician. As well as the extras mentioned above, it also covers areas such as dental anomalies and occlusion, using excellent pictures and diagrams to make the text easy to understand. Despite the large scope of this book it does not withhold the essential details.

I would highly recommend this book to all students; it will see you through dental school and beyond. It is useful for junior years of the BDS course while providing more detailed information for final years and newly qualified dentists.

R. WIGNALL

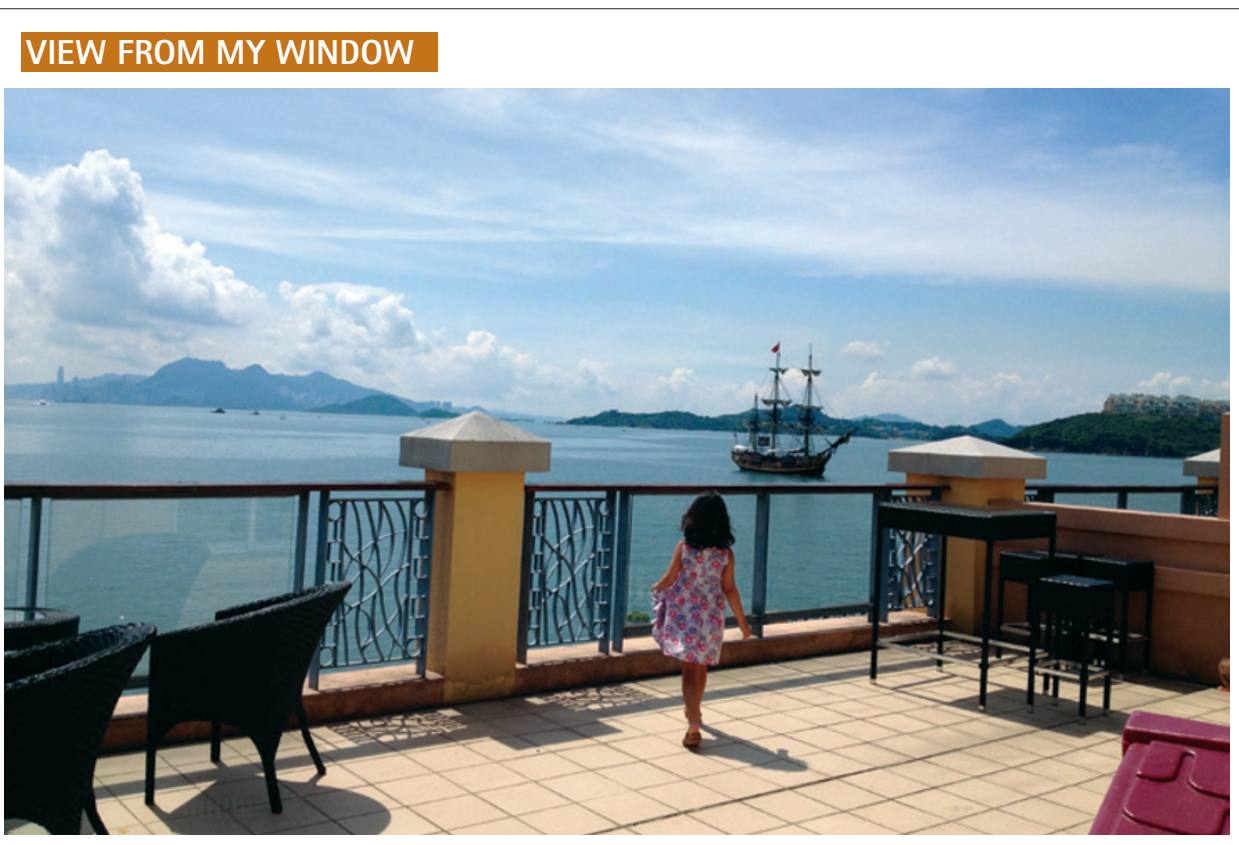

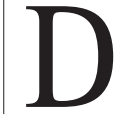
enise Giles sent in this photo of the fabulous view from her dental clinic in Discovery Bay, Lantau Island, Hong Kong. Denise wrote to the $B D J$ : 'This was an unposed photo. I had just arrived for work and my lovely first patient, age seven, ran onto our terrace to look at The Bounty. This is a replica of the tall ship used in the film Mutiny on the Bounty. The skyscrapers of Hong Kong Island are visible in the background.
Denise qualified in Wales but has practised overseas for 33 years and is an international subscriber to the $B D J$.

\section{NEXT CHALLENGE: Send}

photos with the theme 'sharp'. This does not necessarily have to be dental instruments! Email your image to k.quinlan@nature.com. 